\section{UJMM

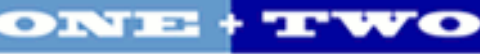

Volume 5 | 2012 Fall

\section{Undergraduate Journal of Mathematical}

Modeling: One + Two

2013

\title{
Volatilization of Benzene in a River
}

Eric Dunlop

University of South Florida, edunlop@mail.usf.edu

Advisors:

Arcadii Grinshpan, Mathematics and Statistics

Scott Campbell, Chemical \& Biomedical Engineering

Problem Suggested By: Scott Campbell

Follow this and additional works at: https://digitalcommons.usf.edu/ujmm

Part of the Environmental Health and Protection Commons, Mathematics Commons, and the Water Resource Management Commons

UJMM is an open access journal, free to authors and readers, and relies on your support: Donate Now

\section{Recommended Citation}

Dunlop, Eric (2013) "Volatilization of Benzene in a River," Undergraduate Journal of Mathematical Modeling: One + Two: Vol. 5: Iss. 1, Article 2.

DOI: http://dx.doi.org/10.5038/2326-3652.5.1.2

Available at: https://digitalcommons.usf.edu/ujmm/vol5/iss1/2 


\title{
Volatilization of Benzene in a River
}

\begin{abstract}
Benzene is a volatile organic compound: when it contaminates a river, some of the substance will evaporate as it flows through. We examine the volumetric flow rate to find how volatilization affects the concentration levels of benzene as the substance flows through several consecutive sections of a river, using a specific example to illustrate the general method.
\end{abstract}

Keywords

Benzene, Volatilization, Environmental Contamination 


\section{PROBLEM STATEMENT}

Given the initial concentration of benzene as it enters a section of a river, what will be its concentration when it reaches the end of the last section of the river?

\section{MOTIVATION}

Benzene is a volatile organic compound (VOC) that appears as a colorless liquid with a sweet odor. It evaporates into the air very quickly, dissolves slightly in water, is highly flammable, and is formed from both natural processes and human activities (Agency for Toxic Substances and Disease Registry). Natural sources of benzene include volcanoes and forest fires. In industry, benzene is used to make other chemicals to produce plastics, resins, and nylon and synthetic fibers. It is also used to make some types of rubbers, lubricants, dyes, detergents, drugs, and pesticides. Additionally, it is a part of crude oil, gasoline, and cigarette smoke (Agency for Toxic Substances and Disease Registry).

Benzene is known to affect human hematological (blood forming), immunological, and neurological organ systems, and is considered to be a human carcinogen. Despite this, it is widely used in the United States, ranking in the top 20 chemicals for production volume. For this reason, it is important to monitor the concentration levels of benzene in bodies of water such as the local rivers, ensuring that contaminated water is treated and drinking water is safe.

The aim of this project is to show how to calculate the concentration of benzene in a river if its concentration is known when it initially enters the river at a known point. Such a method would be a useful tool following a spill, allowing one to determine when water needs to be treated because it is not safe to drink. 


\section{MATHEMATICAL DESCRIPTION AND SOLUTION APPROACH}

As an example for the application of the general method, we will consider a hypothetical case in this project and analyze four sections of varying flow rates and depths along a river. The data for these sections is shown in Table 1.

\begin{tabular}{|c|c|c|c|}
\hline Section & Velocity (ft/s) & Depth (ft) & Length (miles) \\
\hline 1 & 2.8 & 3.5 & 2 \\
\hline 2 & 3.1 & 4.4 & 5 \\
\hline 3 & 3.4 & 3.2 & 8 \\
\hline 4 & 8.6 & 5.2 & 4 \\
\hline
\end{tabular}

Table 1: The hypothetical data for a river having four sections with varying flow rates, depth, and length.

Before proceeding with the example, however, we must first obtain a differential equation describing the change in concentration of benzene as a function of time. We begin with the expression for the volumetric flow rate through a particular cross section of the river:

$$
Q=v \cdot A
$$

where $Q$ is the volumetric flow rate of water in $\mathrm{ft}^{3} / \mathrm{s}, v$ is the velocity of water, and $A$ is the crosssectional area of the river at the point of interest.

Assuming a constant waterbed width $W$, we can write

$$
A=W \cdot h
$$

where $h$ is the depth of the river; and the surface area $S$ along a segment $\Delta z$ of the river can be expressed as $S_{\Delta z}=\Delta z \cdot W$. 
Let $K$ be the mass transfer coefficient in $\mathrm{ft} / \mathrm{s}$. Then $K \cdot S$ gives the evaporation rate, so that if $B(z)$ is the concentration of benzene in parts per billion at some point $z$ and $B(z+\Delta z)$ is the concentration some distance $\Delta z$ further along the river, we can say that

$$
B(z+\Delta z) \cdot Q \approx B(z)\left(Q-K \cdot S_{\Delta z}\right)=B(z)(Q-K \cdot W \cdot \Delta z)
$$

for small $\Delta z$, with the approximation becoming equality as $\Delta z \rightarrow 0$ (the amount of flow decreases by the amount evaporated). Distributing the right hand side, dividing by $Q$ and $\Delta z$, rearranging the terms, and taking the limit we obtain

$$
\lim _{\Delta z \rightarrow 0} \frac{B(z+\Delta z)-B(z)}{\Delta z}=-\frac{B(z) \cdot K \cdot W}{Q}
$$

and since this holds for any $z$, we can write

$$
\frac{d B}{d z}=-\frac{B \cdot K \cdot W}{Q}
$$

Furthermore, since the distance $z=v \cdot t$ and $v$ is assumed to be constant for each section, it follows that $d z=v \cdot d t$, which we can substitute into the above equation so that

$$
\frac{d B}{d t}=-v \cdot \frac{B \cdot K \cdot W}{Q}
$$

and from (1) and (2) we can cancel the terms on the right hand side to obtain the simplified differential equation

$$
\frac{d B}{d t}=-\frac{K B}{h}
$$

which relates the concentration to time as desired. 
Now we can apply this to our hypothetical case. Let the river have the parameters in Table 1 and suppose that the concentration of Benzene when it's discharged at the beginning of the first section is $20 \mathrm{ppb}$. Write that as $B_{0}=20 \mathrm{ppb}$.

To solve the differential equation, we separate the variables, so that

$$
\frac{1}{B} \frac{d B}{d t}=-\frac{K}{h}
$$

and

$$
\int \frac{1}{B} d B=-\frac{K}{h} \int d t
$$

The general solution is $\ln B=-\frac{K}{h} t+C_{0}$, or, equivalently, $B=C e^{-\frac{K}{h} t}$. Since $B(0)=B_{0}$, we can write

$$
B=B_{0} e^{-\frac{K}{h} t}
$$

as the final expression.

The mass transfer coefficient $K$ varies with the characteristics of the velocity and depth.

For this case,

$$
K=0.0004 \frac{v^{1 / 2}}{h^{3 / 2}}
$$

and substituting this expression into the equation for $B$ along with $B_{0}=20$, we get

$$
B=20 e^{-0.0004 t \cdot \frac{v^{1 / 2}}{h^{5 / 2}}}
$$

and using the values from Table 1, we can find the concentration levels for each section of the river, shown in Table 2 . We can divide the length of the section by the velocity to find the 
corresponding time for each section. A plot of concentration as a function of time is given in Figure 1.

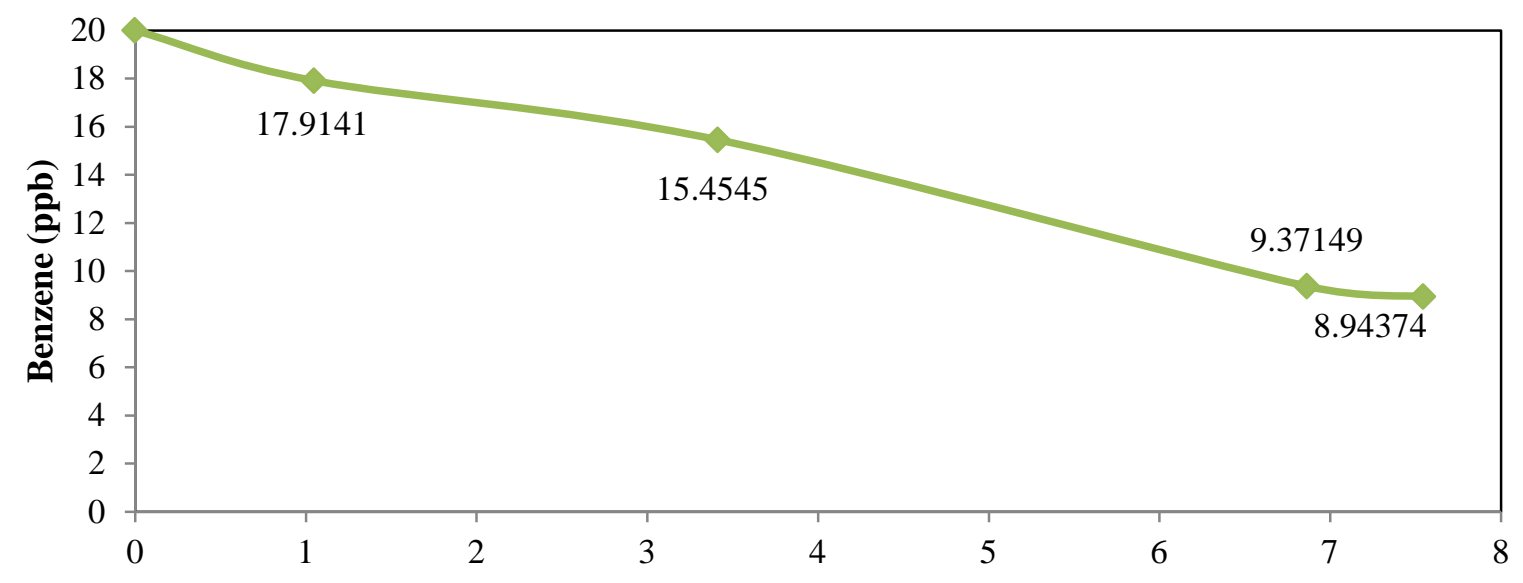

Time (hours)

\begin{tabular}{|c|c|c|c|c|}
\hline Section & Velocity (ft/s) & Depth (ft) & Length (miles) & Concentration (ppb) \\
\hline 1 & 2.8 & 3.5 & 2 & 17.9141 \\
\hline 2 & 3.1 & 4.4 & 5 & 15.4545 \\
\hline 3 & 3.4 & 3.2 & 8 & 9.37149 \\
\hline 4 & 8.6 & 5.2 & 4 & 8.94374 \\
\hline
\end{tabular}

Figure 1: Data from Table 1 with the calculated benzene concentration values for the end of each section.

\section{DISCUSSION}

From Figure 1, we see that it took about 6.5 hours for the benzene levels to drop to half of the initial concentration, but even at the very end, after about 7.5 hours, the concentration was $8.94 \mathrm{ppb}$. The Environmental Protection Agency allows $5 \mathrm{ppb}$ (parts per billion) or $0.005 \mathrm{mg} / \mathrm{L}$ for benzene in drinking water (EPA), therefore this river has a much higher benzene 
concentration than the EPA standard. We can conclude that before this water can be considered safe and used for drinking, it must either travel further down the river so that more of the benzene is evaporated or be processed through a Wastewater Treatment Plant.

\section{CONCLUSION AND RECOMMENDATIONS}

It is worthwhile remembering that benzene and similar contaminants are not only a human health risk, but also a risk to wildlife in the surrounding ecosystems. Therefore these types of hazardous chemicals should be disposed of in a sanitary landfill or an incinerator (City of Tampa).

The goal of the example was to illustrate a model that can be followed for all VOCs that can enter the waterways and potentially contaminate the drinking water. In this paper we made several simplifying assumptions: we assumed the width, the depth, and the velocity of the river to be constant in each section. Of course, by dividing the river into many sections, we could obtain a more accurate result and off-set this shortcoming of the model. More importantly, we assumed that the concentration was even throughout the water. In fact, since benzene is lighter than water, the concentration would be higher toward the surface, with the two liquids eventually separating into two layers. A more accurate model would need to reflect this. Nonetheless, even this simple model is useful for obtaining an initial estimate of the concentration - its advantage being that it is easy to apply. 


\section{NOMENCLATURE}

\begin{tabular}{|c|l|l|}
\hline Variable & Description & Units \\
\hline$A$ & Cross-sectional area of the river & $\mathrm{ft}^{2}$ \\
\hline$B_{0}$ & Initial concentration level of benzene when it enters the river & $\mathrm{ppb}$ \\
\hline$B$ & Concentration level of benzene & $\mathrm{ppb}$ \\
\hline$h$ & River depth & $\mathrm{ft}$ \\
\hline$K$ & Mass transfer coefficient & $\mathrm{ft} / \mathrm{s}$ \\
\hline$Q$ & Volumetric flow rate & $\mathrm{ft}^{3} / \mathrm{s}$ \\
\hline$t$ & Time & $\mathrm{s}$ \\
\hline$v$ & Velocity of the water & $\mathrm{ft} / \mathrm{s}$ \\
\hline$S$ & Surface area of the river & $\mathrm{ft}^{2}$ \\
\hline$W$ & Width of the river & $\mathrm{ft}$ \\
\hline$z$ & Distance traveled by benzene along the length of the river & $\mathrm{ft}$ \\
\hline
\end{tabular}

\section{REFERENCES}

Agency for Toxic Substances and Disease Registry. ATSDR - Toxic Substances - Benzene. 3 March 2011. December 2012

$<$ http://www.atsdr.cdc.gov/substances/toxsubstance.asp?toxid=14 $>$.

City of Tampa. Hazardous Waste. 6 May 2012. December 2012

<http://www.tampagov.net/dept_wastewater/information_resources/hazardous_waste.asp $>$.

EPA. Drinking Water Contaminants. 5 June 2012. December 2012 <http://water.epa.gov/drink/contaminants/index.cfm>. 